\title{
Uso de las imágenes en la pandemia por SARS-CoV-2
}

\section{Use of images in the pandemic for SARS-CoV-2}

\author{
Silvia Lucía Mayanga Sausa,a \\ ${ }^{1}$ Servicio de Radiodiagnostico, Departamento de Imagenología, Hospital Nacional Edgardo Rebagliati Martins. Lima, Perú. \\ a Médico cirujano con especialidad en radiología, miembro de la Sociedad Peruana de Radiología y del Colegio Interamericano de Radiología. ORCID: https://orcid.org/0000- \\ 0002-4924-4976
}

An Fac med. 2020;81(2):248-9. / DOI: https://doi.org/10.15381/anales.v81i2.17805

\section{Correspondencia:}

Silvia Lucía Mayanga Sausa

lumaysa@gmail.com

Recibido: 7 de mayo 2020

Aprobado: 24 de mayo 2020

Publicación en línea: 27 de mayo 2020

Conflictos de interés: La autora declara no tener conflictos de interés.

Fuente de financiamiento:

Autofinanciado

Citar como: TMayanga Sausa SL. Uso de las imágenes en la pandemia por SARS-COV-2. An Fac med. 2020;81(2):248-9. DOI: https://doi. org/10.15381/anales.v81i2.17805

\section{Sr. Editor,}

La actual pandemia del coronavirus SARS-CoV-2 se ha convertido en un reto mundial por las implicancias sociales y económicas que desnudan la situación real de los sistemas de salud, con mayor impacto en los países en desarrollo como el nuestro, donde de las pruebas de laboratorio son escasas, los equipos de protección personal y los equipos médicos son limitados; esta realidad nos enfrenta a diario a la muerte a pacientes y al personal de salud.

El diagnostico de enfermedad por SAR-CoV-2 se basa en las características clínicas y en pruebas de laboratorio (serológicas - inmunológicas); el uso de alguna modalidad de imágenes está supeditada a estos dos parámetros básicos. En el contexto de la pandemia, la utilidad al elegir una modalidad de imágenes es optimizar el diagnóstico y monitorizar las posibles complicaciones que guíen el manejo de la terapia y, además, minimicen el riesgo de contagio al personal de salud ${ }^{(1)}$; también, debemos optimizar los recursos disponibles, por lo tanto, se debe conocer las limitaciones y bondades de cada modalidad de imágenes para elegir el momento y la oportunidad de usarla.

El estudio por imágenes no está indicado en todos los casos con sospecha de enfermedad por SARS-CoV-2, en pacientes con enfermedad clínicamente leve y sin antecedentes de factores de riesgo que puedan agravar su condición no se recomienda el uso de imágenes; en pacientes con clínica de enfermedad moderada - grave sí se debe elegir alguna modalidad de imágenes que complementen al cuadro clínico ${ }^{(1)}$. Cualquier modalidad de imágenes es poco específica para identificar la etiología de la enfermedad pulmonar, sin embargo, en base a los estudios de correlación radio-patológica que han ayudado a establecer patrones que nos orientan en el diagnóstico diferencial.

De las modalidades de imágenes, la TC ha reportado mayor sensibilidad para detectar enfermedad por SAR-CoV-2, sensibilidad reportada de hasta $97 \%{ }^{(2)}$, superando incluso al test RT-PCR (sensibilidad 70\%) ${ }^{(2)}$. Esta alta sensibilidad la convierte en el examen de elección en fases iniciales de la enfermedad ${ }^{(3)}$ y para evaluar las complicaciones pulmonares y cardiacas ${ }^{(4)}$; algunos estudios han reportado utilidad de la TC en la fase pre sintomática de la enfermedad (3). La mayor capacidad de la TC contrasta con la menor disponibilidad de equipos, mayor tiempo de inactividad de la sala de TC por la necesidad de limpieza y desinfección, riesgo de transmisión a trabajadores sanitarios y otros pacientes durante el traslado, consumo de EPP y mayor exposición a la radiación para el paciente ${ }^{(1,5)}$. El Colegio Americano de Radiología (ACR) no recomienda su uso para detectar o como prueba de primera línea para diagnosticar enfermedad por SARS-CoV-2 y debe usarse con moderación reservándose para pacientes hospitalizados y sintomáticos con indicaciones clínicas específicas ${ }^{(6)}$.

Otra modalidad de imagen usada en esta pandemia es la radiografía de tórax, reportado una sensibilidad del $69 \%{ }^{(7)}$, mucho menor que la tomografía, con mayor probabilidad de falsos negativos, sobre todo en las fases pre sintomáticas y en los estadios iniciales de la enfermedad ${ }^{(3,7)}$; sin embargo, puede ser útil en las áreas de emergencia cuando el paciente acude con cuadro clínico moderado-grave y la enfermedad por SAR-CoV-2 está establecida; en los pacientes hos- 
pitalizados se usa para evaluar la progresión de la enfermedad y para diferenciar de otras neumonías lobares sugestivas de sobre infección bacteriana, neumotórax y derrame pleural ${ }^{(1,5)}$. La ACR recomienda la radiografía de tórax en la modalidad portátil la cual se está usando en casos sospechosos/confirmados de pacientes hospitalizados por la facilidad de limpiar los equipos, acortamiento de los tiempos, menor dosis de radiación y menor uso de materiales y recursos ${ }^{(6)}$.

La ecografía torácica es otra modalidad de imágenes que se puede usar para evaluar enfermedad por SAR-CoV-2 y sus complicaciones. Puede realizarse en la cama del paciente, es rápida y no irradia al paciente, pero es una técnica no estandarizada, es operador dependiente lo que dificulta evaluar la evolución solo con ecografía, y además supone mayor exposición al personal que realiza la prueba y depende de la experiencia del operador ${ }^{(5)}$.

La elección definitiva de la modalidad de imagen es finalmente del equipo clínico, que tienen que optimizar el manejo del tratamiento teniendo en cuenta el entorno de atención del paciente, los recursos locales y los diferentes atributos de cada una de las modalidades de imágenes.

\section{REFERENCIAS BIBLIOGRÁFICAS}

1. Rubin GD, Ryerson CJ, Haramati LB, Sverzellati N Kanne JP, Raoof SS, et al. The role of chest imaging in patient management during the COVID-19 pandemic: a multinational consensus statement from the Fleischner Society. Chest. 2020. DOI: https:// doi.org/10.1016/j.chest.2020.04.003.

2. Ai T, Yang Z, Hou H, Zhan C, Chen C, et al. Correlation of chest CT and RT-PCR testing in coronavirus disease 2019 (COVID-19) in China: a report of 1014 cases. Radiology. 2020. DOI: https://doi. org/10.1148/radiol.2020200642

3. Shi H, Han X, Jiang N, Cao, Alwalid O, et al. Radiological findings from 81 patients with COVID-19 pneumonia in Wuhan, China: a descriptive study. Lancet Infectious Diseases. 2020. DOI: https:// doi.org/10.1016/S1473-3099(20)30086-4

4. Driggin E, Madhavan MV, Bikdeli B, Chuich T, Laracy J, Biondi-Zoccai G, et al. Cardiovascular Considerations for Patients, Health Care Workers, and Health Systems During the COVID-19 Pandemic. J Am Coll Cardiol. 2020;75(18):2352-71. DOI: 10.1016/j.jacc.2020.03.031.

5. Sociedad Española de Radiologia Médica [Internet]. Guia básica de indicaciones de pruebas de imagen en la infección COVID-19. (V1. 21/3/2020), 2020 [Fecha de acceso: 13 de mayo de 2020]. Disponible en: https://www.seram.es/images/site/Recomendaciones_imagen_SERAM_COVID_19.pdf

6. American College of Radiology [Internet]. ACR Recommendations for the use of chest radiography and computed tomography (CT) for suspected COVID-19 infection, 11/3/2020 [Fecha de acceso: 13 de mayo de 2020]. Disponible en: https://www. acr.org/Advocacy-and-Economics/ACR-PositionStatements/Recommendations-for-Chest-Radiography-and-CT-for-Suspected-COVID19-Infection 7. Wong HF, Lam HS, Fong-T, Leung ST, Chin TWY, Lo CSY, et al. Frequency and Distribution of Chest Radiographic Findings in COVID-19 Positive Patients. Radiology. 2020. DOI: https://doi.org/10.1148/radiol.2020201160 